\title{
Instalação de uma pequena bacia experimental florestal: estudo de caso da bacia do Rio Araponga
}

\author{
Implementation of a small forested experimental basin: \\ case study of the Araponga river basin
}

Aline de Almeida Mota', Fernando Grison², Joana Nery Giglio³, Masato Kobiyama ${ }^{4}$

$\square$

\begin{abstract}
RESUMO
O presente trabalho detalha aspectos importantes a serem observados nos procedimentos de seleção e caracterização de uma bacia experimental florestal e instalação de um sistema de monitoramento hidrológico, com enfoque em fluviometria, pluviometria e tensiometria. Para tanto, utilizouse a experiência adquirida no estudo de caso da bacia experimental do Rio Araponga (ARA), localizada no município de Rio Negrinho (SC). O levantamento dos pontos de nascentes e confluências permitiu a extração da rede de drenagem mais próxima da realidade considerando a base cartográfica disponível (escala 1:10.000). A determinação dos locais adequados dos aparelhos de monitoramento hidrológico foi possível somente com levantamento topográfico mais detalhado (escala 1:5.000).
\end{abstract}

Palavras-chave: monitoramento hidrológico; pequena bacia experimental; tensiometria.

\begin{abstract}
The objective of the present paper was to detail important aspects that should be considered for the selection and characterization of a forested experimental basin. Furthermore, the implementation of a hydrological monitoring system, focusing on runoff, rainfall, and tensiometric monitoring, was detailed. The description was based on the experience obtained in the case study of experimental Araponga basin river (ARA), located in the city of Rio Negrinho (SC). Points located on springs and river confluences were surveyed. Using these points, a drainage network closer to reality could be extracted from the base map at 1:10,000 scale. The determination of adequate locality of hydrological monitoring equipment was possible only with the topographic survey at 1:5,000 scale.
\end{abstract}

Keywords: hydrological monitoring; small experimental basin; tensiometry.

\section{INTRODUÇÃO}

As atividades de monitoramento hidrológico subsidiaram o surgimento e avanço dos principais conceitos da hidrologia (NACE, 1974). Os trabalhos que renderam aos cientistas Pierre Perrault, Edme Mariotte e Edmond Halley o título de fundadores da hidrologia como ciência e esclareceram dúvidas sobre o ciclo hidrológico se basearam em experimentos de monitoramento hidrológico (TODD;MAYS, 2005).

O monitoramento hidrológico é também fundamental ao planejamento, ao aproveitamento e à conservação dos recursos hídricos, pois estes não podem ser gerenciados apropriadamente a menos que se tenham informações sobre onde estão, em que quantidade e qualidade e o quão variáveis podem ser em um futuro previsível (STEWART, 2015).
Segundo a Lei no 9.433, de 8 de janeiro de 1997 (BRASIL,1997), parte do conteúdo mínimo do Plano de Recursos Hídricos, um dos principais instrumentos da Política Nacional de Recursos Hídricos (PNRH), depende da disponibilidade de dados hidrológicos, tanto para a realização do diagnóstico da situação atual dos recursos hídricos quanto para a análisede cenários futuros de uso por meio de modelagem.

A bacia hidrográfica é a unidade territorial para implementação da PNRH (BRASIL, 1997), e é essencial o uso de bacias experimentaispara estudos hidrológicos científicos. Nessa mesma lógica, Uhlenbrook (2006) enfatiza a importância de avançar a denominada "hidrologia de bacia”.O primeiro estudo com bacias experimentais no mundo, no qual duas bacias foram analisadas, foi realizado na Suíça, em 1902

'Doutoranda em Recursos Hídricos e Saneamento Ambiental da Universidade Federal do Rio Grande do Sul (UFRGS).Professora do Curso de Engenharia Ambiental da Universidade Federal da Fronteira Sul (UFFS) - Chapecó (SC), Brasil.

2Doutor em Engenharia Ambiental pela Universidade Federal de Santa Catarina (UFSC). Professor do Curso de Engenharia Ambiental da UFFS - Chapecó (SC), Brasil. ${ }^{3}$ Mestre em Engenharia Ambiental pela UFSC. Especialista em Meio Ambiente e Recursos Hídricos do Instituto do Meio Ambiente e Recursos Hídricos da Bahia (Inema) Salvador (BA), Brasil.

${ }^{4}$ Doutor em Engenharia Florestal pela Universidade Federal do Paraná (UFPR). Professor no Instituto de Pesquisas Hidráulicas da UFRGS - Porto Alegre (RS), Brasil. Endereço para correspondência: Aline de Almeida Mota - UniversidadeFederal da Fronteira Sul - Avenida Fernando Machado, 108 E - Centro - CEP: $89802-112$ - Chapecó (SC), Brasil - E-mail: aline.mota@uffs.edu.br

Recebido: 20/09/15 - Aceito: 27/O4/16 - Reg. ABES: 154610 
(WHITEHEAD;ROBINSON, 1993). O segundo foi em 1906 no Japão (NAKANO, 1976). Posteriormente, no início do século XX foram iniciados estudos semelhantes nos Estados Unidos, na Europa e na África do Sul. Hoje existem diversas bacias experimentais no Brasil e no mundo.

A variabilidade espaçotemporal da quantidade e qualidade dos recursos hídricos está fortemente relacionada aos fatores de cobertura e manejo do solo, pedologia, clima, entre outros. Mendonça et al. (2009) mostraram que a diminuição da capacidade de infiltração contribui para a redução da quantidade de água armazenada no solo e para o aumento de estresse hídrico na vegetação local, auxiliando na redução da recarga do aquífero. Souza e Gastaldini (2014) comprovaram a interferência dos usos do solo de quatro bacias hidrográficas na qualidade da água. Então, no intuito de garantir a conservação de ecossistemas, é fundamental entender as interações entre seus componentes.

Nesse sentido, entre as diretrizes gerais de ação para implementação da PNRH, está a articulação da gestão de recursos hídricos tanto com a gestão ambiental como com a do uso do solo (BRASIL, 1997). Além disso, no Brasil, os atos normativos que visam à proteção dos remanescentes de floresta ombrófila mista (FOM) e do bioma mata atlântica trazem, no mesmo nível de importância, a salvaguarda da biodiversidade e do regime hídrico (BRASIL, 2002; 2006). Esses remanescentes encontram-se em pequenos fragmentos, sendo uma importante justificativa para o monitoramento de pequenas bacias.

No entanto a instalação e coleta de dados hidrológicos no Brasil tiveram como seu principal agente o setor de geração de energia elétrica. Logo, na rede de monitoramento hidrológico nacional, apesar de reconhecida a relevância das pequenas bacias hidrográficas para o gerenciamento de recursos hídricos, há poucos postos fluviométricos em bacias com menos de $500 \mathrm{~km}^{2}$ (GOLDENFUM, 2001).

Existem diversas publicações fruto de pesquisas quanto à hidrologia em pequenas bacias experimentais implementadas em território nacional (DE OLIVEIRA LEITE, 1985; FUJIEDA; KUDOH; MASHIMA, 1993; FUJIEDA et al., 1997; ALMEIDA; SOARES, 2003; CHAFFE et al., 2010; GOMES et al., 2012; MARANGON; SANTOS, 2012). Porém, como o enfoque dessas publicações não era a descrição de materiais e métodos acerca de como instalar bacias experimentais, muitos detalhes importantes sobre a implementação do sistema de monitoramento e a obtenção dos dados foram suprimidos. Nessa perspectiva, verificou-se uma deficiência no que diz respeito à descrição técnico-científica que serviria como guia para a instalação de monitoramento em bacias de pequena ordem.

Diante disso, o objetivo do presente trabalho foi detalhar aspectos importantes a serem observados nos processos de identificação, seleção e caracterização de uma bacia experimental florestal e instalação de um sistema de monitoramento hidrológico, com enfoque em fluviometria, pluviometria e tensiometria. Para tanto,utilizou-se a experiência adquirida no estudo de caso da bacia experimental do Rio Araponga (ARA), localizadana área rural do município de Rio Negrinho (SC).

\section{METODOLOGIA}

A primeira etapa de uma pesquisa em hidrologia que envolva monitoramento consiste em definir a escala de observação adequada para os processos hidrológicos que se pretende compreender. Como foi mencionado na Introdução, estudos em pequenas bacias foram e têm sido muito produtivos e importantes para o avanço da hidrologia e, por consequência, da gestão de recursos hídricos. No caso de investigar o mecanismo de geração de vazão no contexto do ciclo hidrológico, por meio de pesquisa na literatura técnico-científica, concluiu-se que a escala apropriada seria a de bacia. Então foi necessário buscar uma bacia hidrográfica adequada para o propósito do estudo e, em seguida, implementar o sistema de monitoramento hidrológico.

O primeiro passo depois de definir os objetivos do estudo foi elencar as características básicas da bacia a ser instrumentada. Como a intenção final da pesquisa era compreender os mecanismos de geração de vazão em uma bacia de características naturais preservadas, a bacia a ser monitorada deveria ser pequena e totalmente coberta por vegetação nativa (no presente estudo, FOM).

\section{Identificação de uma bacia adequada para monitoramento}

A instalação do sistema de monitoramento hidrológico em geral se inicia pela seleção da seção de monitoramento fluviométrico. Isso porque o delineamento da bacia hidrográfica depende do posicionamento do exutório onde normalmente fica a estação fluviométrica. Como a instalação em si envolve o dispêndio de recursos financeiros e humanos,é necessário fazer um planejamento bem detalhado a fim de encontrar o melhor local possível.

Apesar de terem sido realizadas diversas idas a campo seguidas de posteriores estudos em escritório, foram evidenciadas apenas as quatro visitas mais decisivas para a escolha da bacia do Rio Araponga.

Na primeira visita à área (em 13 de julho de 2010), fomos guiados pelo funcionário da empresa Battistella Florestal José Lucindo (Porungo), que conhecia muito bem as áreas rurais da região do município de Rio Negrinho, estado de Santa Catarina, e sabia indicar uma área com as características desejadas. Uma das áreas até a qual Porungo nos conduziu foi considerada interessante para o estudo. Então, foram coletados pontos onde identificamos potencial para ser o exutório da bacia utilizando o aparelho GarminGPSmap 76CSx. No escritório (Laboratório de Hidrologia LabHidro - da Universidade Federal de Santa Catarina - UFSC), os pontos foram plotados e a bacia localizada e previamente delimitada na ortofotocarta digital, em escala 1:10.000, cedida pela Secretaria de Planejamento e Meio Ambiente (Seplan) da Prefeitura de Rio Negrinho. Essa etapa foi de suma importância, pois, como se buscava uma bacia caracterizada por floresta nativa, a área investigada seria descartada caso fosse identificado qualquer outro uso/cobertura do solo predominante. Apenas uma pequena porção com plantação de pinus na cabeceira da bacia foi identificada.

A segunda visita (em 4 de outubro de 2010) deu-se para confirmar as condições de uso/cobertura do solo identificadas remotamente. Isso é 
muito importante, pois na maioria das vezes as imagens aéreas disponíveis representam situações passadas, então é necessário confirmar tais condições. Procurou-se verificar os divisores de água, sobretudo na cabeceira da bacia, no intuito de visitar a pequena área de floresta não nativa identificada na ortofoto e averiguar suas características pessoalmente. Como essa área era muito pequena em relação àárea da bacia (cerca de 3\%) e a plantação de pinus apresentava uma pequena modificação referente ao solo, considerou-se que a presença dessa pequena área de pinus não seria um impedimento para a escolha dessa bacia hidrográfica caracterizada por floresta nativa. Nessa ocasião, percorreu-se também a rede de drenagem com a intenção de reconhecer suas nascentes e o rio principal, além de encontrar mais alternativas de seção para a instalação da estação fluviométrica.

Após a decisão pela área, era preciso definir o local para instalação da estação fluviométrica. Na terceira visita (no dia 22 de novembro de 2010), dois locais foram vistos como apropriados para a instalação da estação fluviométrica, porém o mais a jusante demonstrou uma característica negativa: a existência de uma várzea na margem esquerda. Isso poderia ter o efeito de retardar o fluxo de água e assim interferir na medição de nível no exutório da bacia. Como o objetivo do trabalho não era avaliar a influência da várzea, esse local foi descartado. Após a escolha da seção, foram medidas suas principais dimensões e a inclinação média do trecho a montante da seção a fim de pré-projetar o dispositivo hidráulico a ser instalado na estação fluviométrica. Para tanto, precisava-se conhecer o intervalo aproximado de vazões que se pretendia medir. Nas observações em campo foram estimadas vazões da ordem de $2 \mathrm{~L} \cdot \mathrm{s}^{-1}$, considerada a vazão da época seca, e pelo uso do método racional foi estimada a vazão de pico para a bacia de aproximadamente $140 \mathrm{~L} \cdot \mathrm{s}^{-1}$. Então, da seção e do intervalo de vazões em diante, foi feito o projeto da estação fluviométrica. Optou-se por utilizar o vertedor triangular de $90^{\circ}$, pois, além de amplamente utilizado em estudos hidrológicos em pequenas bacias, atendia ao intervalo de vazões necessário.

$\mathrm{Na}$ quarta visita (em 8 de janeiro de 2011), para confirmação das dimensões do vertedor triangular, foi cortada uma chapa de compensado de madeira em dimensões idênticas à chapa de aço projetada. $\mathrm{O}$ rio foi barrado com a chapa de madeira apoiada em pedras coletadas no próprio local. Assim, foi simulada a situação de instalação do projeto, e verificou-se seu bom funcionamento. Isso significa que a água verteu, criando uma porção de ar entre a lâmina e a chapa (sem "colar"), e não criou um lago muito extenso a montante.

\section{Instalação da estação de monitoramento fluviométrico automático}

No exutório da bacia foi instalada a estação fluviométrica composta por vertedor triangular $90^{\circ}$ de parede fina (biselada $45^{\circ}$ ), régua linimétrica e sensor de pressão. O vertedor foi construído em chapa de aço inoxidável cortada em V, apoiada em dois muros de alvenaria, um em cada lado da seção transversal (Figuras 1A e B). A régua linimétrica foi chumbada no leito do rio, encostada na margem esquerda e a montante do vertedor uma distância suficiente para evitar a influência do rio sobre a lâmina d'água (Figuras 1C e D). Porto (2006) recomenda que essa distância seja de seis a 10 vezes maior que a carga sobre o vertedor.

Realizou-se o monitoramento automático por meio de sensor de pressão da marca WaterLOG ${ }^{\circledR}$, modelo H-310, e datalogger da mesma marca, modelo $\mathrm{H}-500 \mathrm{XL}^{\mathrm{TM}}$. Salienta-se que é importante selecionar o sensor adequado para o intervalo de valores (aqui, altura de coluna d’água) que se pretende medir.

Criou-se uma estrutura para fixar o sensor e protegê-lo de detritos transportados pelo rio. A estrutura é composta por um tubo de policloreto de polivinila (PVC) de $150 \mathrm{~mm}$ de diâmetro e comprimento aproximado de 1,5 m conectado a uma curva de $90^{\circ}$. O tubo foi posicionado a montante do vertedor, na mesma seção transversal que a régua linimétrica, encostado na margem direita, e foi chumbado com cimento no leito do rio, em posição vertical (aferida por nível de pedreiro), com a curva na extremidade inferior (Figuras 1D e E). O sensor foi posicionado na extremidade inferior do tubo dePVC, ou seja, na junção com a curva de $90^{\circ}$. Assim, a altura da coluna d’água dentro do tubo equivale à da seção transversal no rio.

O intervalo de monitoramento também é um fator que requer atenção. Deve sempre ser menor que o tempo de concentração da bacia e adequado aos objetivos do estudo. Como na maioria das vezes não se têm informações para calcular o tempo de concentração da bacia, pois a estação fluviométrica é o começo do monitoramento hidrológico, podem-se utilizar fórmulas empíricas para estimá-lo, como, por exemplo, as fórmulas de Kirpich (1940), de Loukas e Quick (1996), de Simas e Hawkins (1996), entre outras. Porém o intervalo não deve ser tão pequeno de modo que o conjunto de medidas ultrapasse a capacidade máxima de armazenamento do datalogger, o que depende também da frequência com que se pretende realizar as campanhas de manutenção das estações. No presente trabalho, usou-se o intervalo de medição de 5 minutos.

Logo nas primeiras campanhas demanutenção, percebeu-se que muitas folhas e galhos se acumulavam no vertedor, e isso acarretava erros na medição de nível. Então foi instalada uma tela com uma armação que protege o lago formado pelo vertedor e não impede o fluxo do rio (Figura 1D).

\section{Dados fluviométricos}

Após a instalação da estação fluviométrica,ainda eram necessários alguns cálculos antes de se obter a série temporal de vazões:

1. computar a série temporal de medidas na régua linimétrica (Régua) com base nas alturas de coluna d'água medidas no sensor (Sensor);

2. "transformar" a série temporal de medidas na régua linimétrica (Régua) em série temporal de carga no vertedor $\left(H_{\mathrm{v}}\right)$;

3. calcular a série temporal de vazões $(Q)$ com base nos valores de carga no vertedor utilizando a equação do vertedor.

Durante o monitoramento, percebeu-se que a diferença entre a medição do sensor e na régua não era constante. Então, com 31 medidas concomitantes de nível no sensor e na régua, foi estabelecida a 
Equação $1(\mathrm{R} 2=0,98)$, que permite o cálculo da série contínua de dados de nível do sensor para o correspondente na régua linimétrica.

Régua $=0,7075 \mathrm{x}$ Sensor $+0,0699$

onde:

Régua e Sensor são os níveis medidos na régua e pelo sensor, respectivamente, ambos em metros.

Com o uso do nível topográfico, mediu-se o desnível de 0,164 m entre o zero da régua e o vértice do vertedor. Assim, a carga hidráulica no vertedor é a medida na régua subtraída do desnível de 0,164 m.

Utilizando balde e cronômetro, realizaram-se nove medições de vazão (no intervalo de 0,29 a 12,40 L.s $\mathrm{s}^{-1}$ ), que foram ajustadas à carga hidráulica do momento da medição para gerar a equação do vertedor (Equação 2), com $\mathrm{R}^{2}$ de 0,99 .

$$
Q=1,0368 H v^{2,2682}
$$

onde:
Q é a vazão, $\mathrm{em} \mathrm{m}^{3} \cdot \mathrm{s}^{-1}$;

$H v$ é a carga hidráulica no vertedor (= Régua -0,164), em metros.

\section{Levantamento topográfico e obtenção de parâmetros morfométricos}

Para os estudos preliminares foi utilizada a ortofotocarta digital $\mathrm{n}^{\circ} 23$, em escala 1:10.000, cedida pela Secretaria de Planejamento e Meio Ambiente (Seplan). A escala da cobertura aerofotogramétrica foi 1:20.000, e realizaram-se o voo em abril de 2005 e a restituição em julho de 2006. Porém, como se trata de uma pequena bacia, identificou-se a necessidade de uma base cartográfica mais detalhada. Para tanto, foi feito o levantamento topográfico de toda a área da bacia, com coleta de 1.690 pontos, incluindo estações e os pontos irradiados, sendo a densidade média de pontos na área levantada de 2,5 pontos/100 $\mathrm{m}^{2}$ (Figura 2A).

Com base no levantamento planialtimétrico da bacia, fez-se uso do conjunto de ferramentas ArcHydro para gerar a rede de drenagem da bacia. Uma dificuldade para a extração da rede de drenagem a partir da base topográfica é a definição do valor mínimo de área de acumulação (limiar - em inglês: threshold value) a partir do qual se estabelece

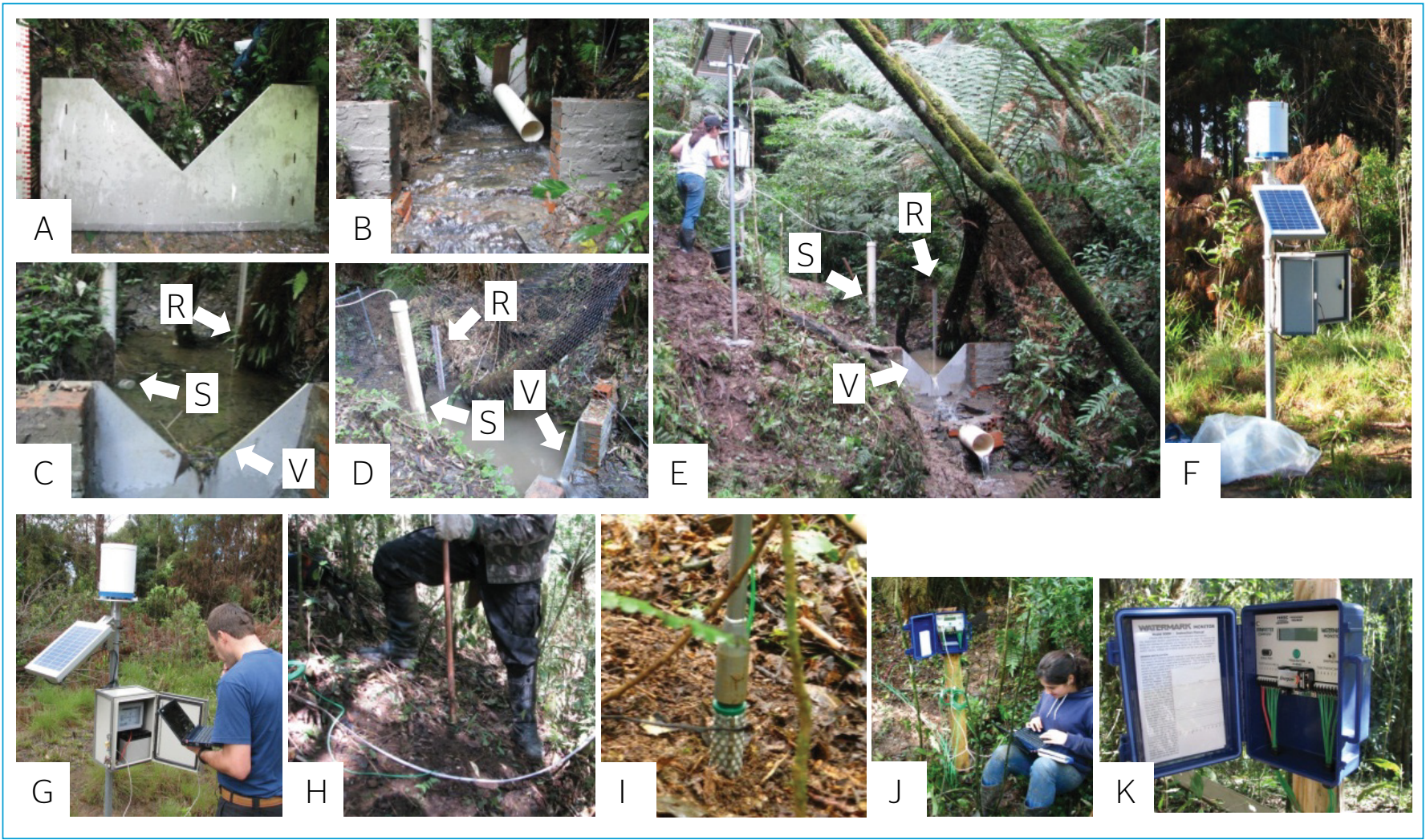

Figura 1 - Instalação do monitoramento hidrológico: (A) chapa de aço e régua linimétrica antes da instalação; (B) muros de alvenaria para apoio da chapa de aço; (C) estação fluviométrica no início do monitoramento: sem a tela, folhas e galhos acumulados no vertedor; (D) estação fluviométrica com a tela instalada; (E) estação fluviométrica completa: régua linimétrica, vertedor, sensor de nível, datalogger, painel solar; (F) estação pluviométrica; (G) transferência de dados pluviométricos; (H) perfuração do solo com o trado apropriado; (I) inserção do sensor de tensão da água no solo; (J) programação do conjunto de monitoramento tensiométrico; $(K)$ datalogger do conjunto de sensores de tensão e temperatura da água no solo. Nota-se que $\mathrm{R}$ indica a posição da régua linimétrica, $\mathrm{S}$ do poço onde está instalado o sensor de pressão, e $\mathrm{V}$ o vertedor. 
a nascente dos rios. No intuito de tentar tornar esse processo menos subjetivo, foram levantados também pontos com sistema de posicionamento global (GPS) nos locais de nascentes, confluências e cursos d’água. Então, o procedimento consistiu em testar diversos valores para o limiar até que se obtivesse a rede de drenagem com os pontos de nascentes e confluências mais coerentes com a realidade de campo (Figura 2B).

\section{Seleção de local adequado e instalação da estação pluviométrica}

Os dados pluviométricos devem ter a maior representatividade possível. Normalmente a medição da chuva é pontual, apesar de apresentar variabilidade espacial influenciada por diversos fatores, sendo o relevo um dos mais importantes (UHLENBROOK, 2006). Então, a bacia foi caracterizada quanto ao relevo utilizando o resultado do levantamento topográfico, e foram realizadas observações em campo durante eventos de chuva. Isso permitiu definir a quantidade mínima de estações pluviométricas e sua localização. Em pequenas bacias, como a Araponga, em geral a variabilidade espacial da chuva não é significativa. Logo,concluiu-se que uma estação pluviométrica seria suficiente.

Além disso, também devem ser observadas a altura e a distância de obstáculos que podem agir obstruindo a chuva ou concentrando-a no pluviógrafo. É evidente que isso deve ser evitado, pois pode acarretar erros na medição.

No entorno do local considerado mais adequado para a instalação da estação pluviométrica existiam algumas árvores de pinus, as quais puderam ser cortadas por meio de autorização e apoio da empresa Battistella Florestal. A distância mínima $(D)$ entre o pluviógrafo (ou pluviômetro) e os obstáculos ao seu redor, recomendada por Santos et al. (2001), deve ser (Equação 3):

$D>2(O-P)$

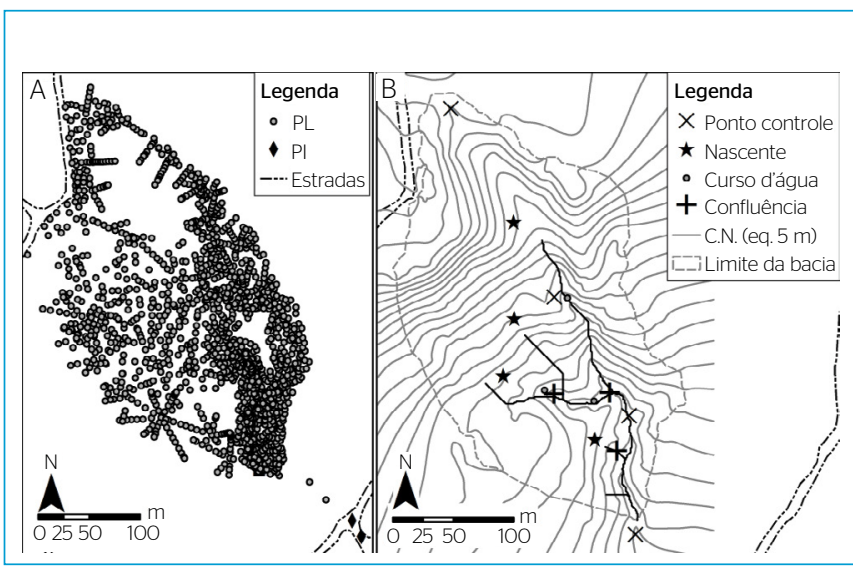

Figura 2 - Levantamento topográfico: (A) Pontos do levantamento topográfico (PL) e pontos de início localizados na estrada (PI); (B) Pontos coletados com GPS e utilizados como referência para a extração da rede de drenagem e pontos de controle do levantamento. C.N. são curvas de nível com equidistância de $5 \mathrm{~m}$. onde:

$D$ é a distância mínima recomendada;

$O$ é a altura de cada obstáculo;

$P$ é a altura do pluviômetro, ou pluviógrafo, todos em metros.

A estação instalada é composta por: pluviógrafo e datalogger da marca WaterLOG ${ }^{\circ}$, modelos H-340 e H-500XL ${ }^{\mathrm{Tx}}$, respectivamente (Figura 1F e Figura 1G). O pluviógrafo apresenta sistema de medição de básculas, com resolução de $0,2 \mathrm{~mm}$. O intervalo de registro adotado foi de 5 minutos. A estação está localizada no divisor de águas da bacia (Figura 4C), a $1.006 \mathrm{~m}$ acima do nível do mar, e o pluviógrafo, instalado a 1,5 $\mathrm{m}$ da superfície do solo.

\section{Monitoramento tensiométrico}

Antes da instalação dos sensores de tensão da água no solo, foi necessária a inspeção da profundidade do solo e do perfil do solo nas vertentes escolhidas para o monitoramento tensiométrico. Com base nessa inspeção, foram determinadas as profundidades para os sensores, de modo a distribuí-los ao longo do perfil de solo. Em cada vertente foi traçada uma linha imaginária partindo do rio (e perpendicular a ele) até o divisor de águas da encosta. Em seguida, quatro conjuntos de tensiômetros foram distribuídos em cada vertente da seguinte maneira: dois mais próximos ao rio (conectados a um único datalogger), um na porção central da vertente, e o último mais próximo do divisor da bacia (Figura 4C).

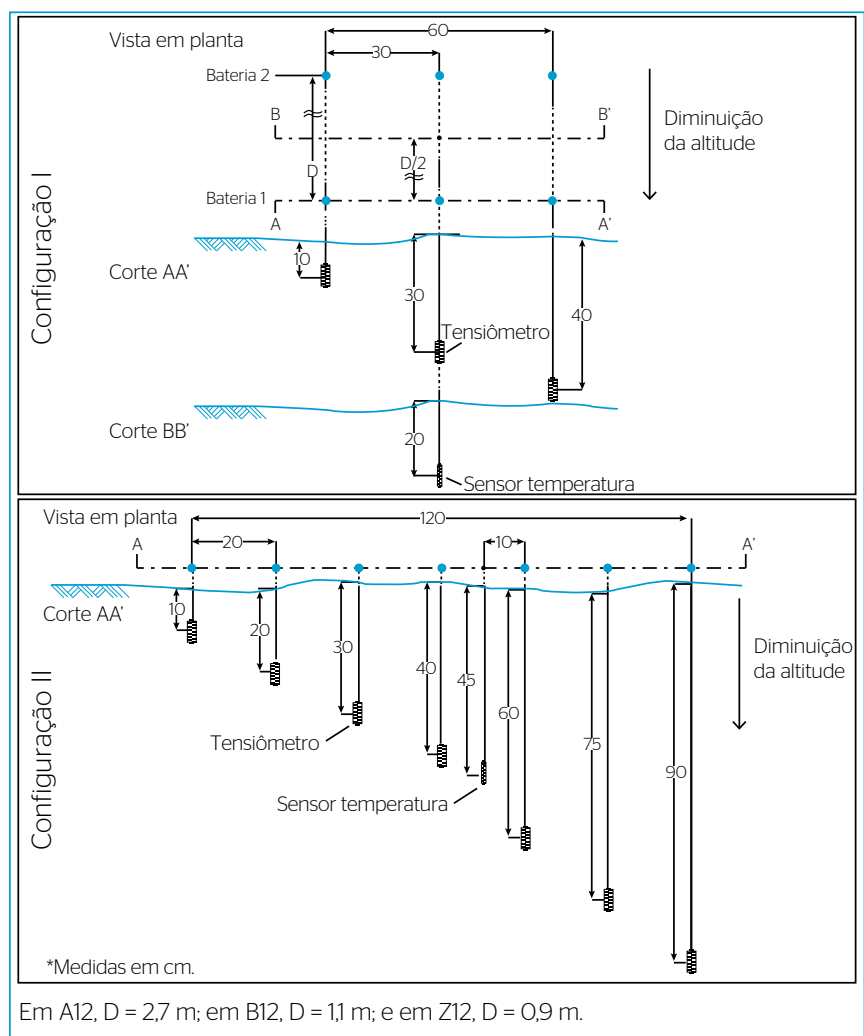

Figura 3 - Configuração tipo l e ll de tensiômetros (vista em planta e cortes). 
No ponto mais próximo ao rio, a declividade da encosta é mais elevada, e então a profundidade de solo média encontrada foi de $0,5 \mathrm{~m}$. Já nos outros dois pontos (na parte central da encosta e mais próximo do divisor) a declividade é menor, e as profundidades variam de 1,0 a 1,9 m. Portanto, optou-se por adotar duas configurações diferentes para os perfis de tensiômetros em função da distribuição de profundidades de solo na encosta. A primeira, denominada tipo I, foi utilizada nos pontos mais próximos ao rio (A12, B12 e Z12). Nos demais pontos, ou seja,na parte central da encosta e próximo do divisor (A3, A4, B3, B4, Z3 e Z4), os sensores foram instalados de acordo com a segunda configuração, denominada tipo II (Figura 3).

Os equipamentos empregados são de fabricação da marca IrrometerWatermark, modelo 200SS. Cada conjunto de tensiômetros é composto por sete sensores de tensão da água no solo, um sensor de temperatura e um datalogger. Na configuração do tipo I, um dos sensores de tensão não foi utilizado; nas demais foi instalado o conjunto completo. O princípio dos sensores é a resistência elétrica no meio poroso.

Após a decisão de posicionamento dos sensores, o procedimento de instalação consiste em perfurar o solo (Figura $1 \mathrm{H}$ ) nos locais determinados até a profundidade que deve ficar cada sensor. É muito importante atentar para o fato de que o sensor tem um comprimento, e então a profundidade de medição é obtida exatamente no plano central do sensor. Por exemplo, para instalar o sensor na profundidade de $20 \mathrm{~cm}$, como o sensor de tensão usado tem comprimento total de $5 \mathrm{~cm}$, é necessário perfurar com o trado até a profundidade de $22,5 \mathrm{~cm}$. Somente dessa maneira se pode considerar que a medição de tensão da água no solo está sendo realizada na profundidade de $20 \mathrm{~cm}$. E assim sucessivamente com todas as profundidades.

O sensor Irrometer pode ser acoplado a um cano de material PVC, que segundo o fabricante tem o intuito de proteger o cabo do sensor. Entretanto esse cano poderia criar uma descontinuidade no meio poroso e um possível caminho de fluxo preferencial da água, afetando a medição de tensão da água no solo. Optou-se pela menor intervenção possível no ambiente, isto é, a instalação foi realizada sem o cano, ficando o cabo do sensor diretamente no solo. Dessa maneira, após a inserção do sensor utilizando um trado específico (Figura 1I), o orifício por onde ele foi inserido foi preenchido com solo do local coletado previamente à instalação, seco à temperatura ambiente e destorroado em laboratório. Após a inserção de cada sensor, foi importante colar uma fita de identificação no cabo de cada sensor. Assim, evitou-se qualquer equívoco durante a etapa final de instalação, que é a ligação dos sensores no datalogger (Figuras $1 \mathrm{~J}$ e K).

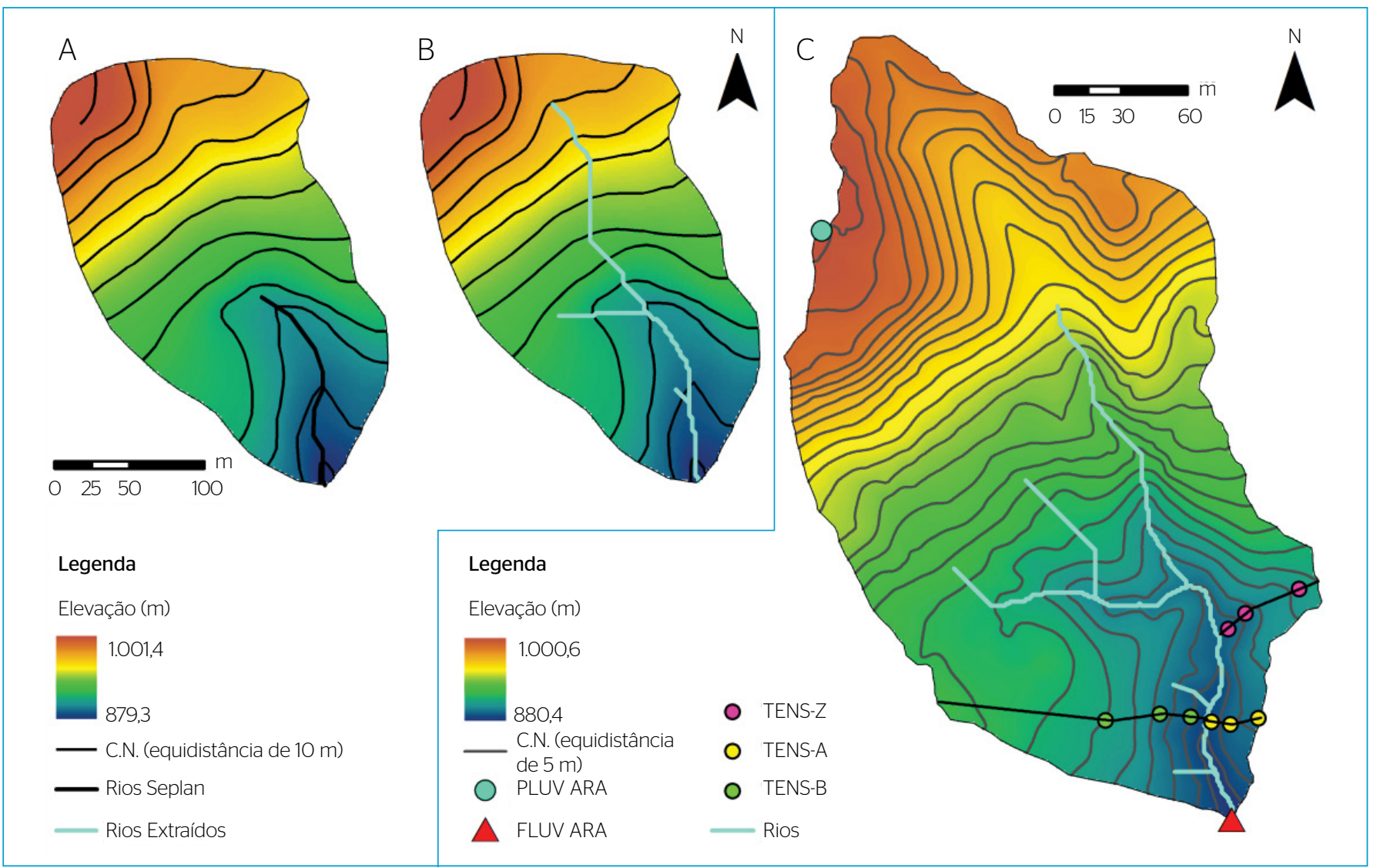

Figura 4 - Evolução da caracterização topográfica da bacia do Rio Araponga. Base cartográfica do levantamento aéreo da Prefeitura de Rio Negrinho, escala 1:10.000, resolução do Modelo Digital de Elevação 2 m, (A) com a rede de drenagem original (Rios Secretaria Municipal de Planejamento); (B) com a rede extraída com base no valor do limiar ajustado (Rios Extraídos); (C) Base cartográfica obtida por meio do levantamento topográfico, escala 1:5.000, resolução do Modelo Digital de Elevação: $1 \mathrm{~m}$. 


\section{RESULTADOS E DISCUSSÃO}

As observações de campo descritas mostraram que a base cartográfica da Seplan (escala 1:10.000) (Figura 4A) não representava adequadamente a realidade de campo. Então, utilizando esses mesmos dados de altimetria, foi possível obter uma rede de drenagem muito mais fidedigna apenas ajustando o valor do limiar com a observação da rede de drenagem que respeitava os pontos de nascentes e confluências levantados em campo, e o rio foi caracterizado finalmente como de segunda ordem (Figura 4B).

Com o Modelo Digital de Elevação (MDE) obtido da interpolação dos pontos do levantamento topográfico, chegou-se a um detalhamento muito maior da topografia da bacia em relação ao material cartográfico anteriormente disponível. Também, a delimitação da bacia alterou-se e identificaram-se encostas muito mais declivosas (Figura 4C).

A maioria dos parâmetros morfométricos calculados estava subestimada utilizando a base de menos detalhes. Os parâmetros relacionados ao comprimento da drenagem e à área da bacia foram os que apresentaram as maiores diferenças, seguidos pela diferença aproximada de $22 \%$ no perímetro (Tabela 1 ).

O sistema de monitoramento automático de vazão, chuva e tensão da água no solo instalado na pequena bacia florestal Araponga permite a coleta concomitante de dados das referidas variáveis. A localização adequada dos aparelhos somente foi possível com base no levantamento topográfico, que gerou dados altimétricos com maior riqueza de detalhes (Figura $4 \mathrm{C}$ ).

Nessa bacia, foram instalados tensiômetros em três linhas transversais ao rio ( $\mathrm{A}, \mathrm{B}$ e $\mathrm{Z}$ ) e em três locais ao longo das linhas: próximo ao rio, no meio da encosta e próximo ao divisor da bacia (Figura 4C). Esse detalhamento foi necessário para compreender a dinâmica da água na encosta. Tal dinâmica é de extrema importância na investigação científica sobre a geração de vazão em bacias hidrográficas (KIRKBY, 1978; ANDERSON; BURT, 1990; UCHIDA et al., 2005).

Observando a bacia (Figura 4C), nota-se que as declividades das encostas de margem direita e esquerda do rio principal são diferentes. Por isso, as linhas TENS-A e TENS-B foram instaladas. Além disso, identificou-se a existência de uma ordem zero na bacia. Hidrologicamente, a ordem zero

Tabela 1 - Parâmetros morfométricos em duas diferentes escalas.

\begin{tabular}{l|c|c|c|c} 
Parâmetro & Unidade & $1: 10.000$ & $1: 5.000$ & Diferença (\%) \\
\hline Área & $(\mathrm{ha})$ & 4,24 & 5,26 & 24,1 \\
\hline $\begin{array}{l}\text { Comprimento } \\
\text { da drenagem }\end{array}$ & $(\mathrm{m})$ & 364,80 & 506,25 & 38,8 \\
\hline $\begin{array}{l}\text { Densidade de } \\
\text { drenagem }\end{array}$ & $\left(\mathrm{m}^{\mathrm{m}} \mathrm{m}^{-2} \cdot \mathrm{0}^{-3}\right)$ & 8,60 & 9,62 & 11,9 \\
\hline $\begin{array}{l}\text { Perímetro } \\
\text { Cota nascente }\end{array}$ & $(\mathrm{m})$ & 817,57 & 994,21 & 21,6 \\
\hline $\begin{array}{l}\text { Cota exutória } \\
\text { Comprimento }\end{array}$ & $(\mathrm{m})$ & 879,31 & 880,67 & $-0,6$ \\
\hline $\begin{array}{l}\text { do rio principal } \\
\text { Declividade } \\
\text { média do canal }\end{array}$ & $(\mathrm{m})$ & 292,25 & 276,62 & $-5,3$ \\
\hline
\end{tabular}

apresenta um comportamento diferente em comparação com outras regiões (TSUBOYAMA et al., 2000). Para entender o efeito hidrológico dessa ordem zero, o presente estudo instalou a linha TENS-Z de tensiômetros.

\section{CONCLUSÕES}

A instalação de uma pequena bacia experimental, como a bacia do Rio Araponga, requer cautela na execução de cada procedimento: identificação prévia da bacia, seleção da seção de monitoramento fluviométrico, localização da estação pluviométrica e dos sensores de tensão da água no solo. Ainda assim, ocorrem muitas dificuldades, as quais a maior parte não está descrita na literatura técnico-científica. Então, textos científicos que trazem mais detalhes sobre a prática e possíveis equívocos dos sistemas de monitoramento hidrológico podem contribuir para o avanço da ciência. Embora existam diversos livros brasileiros sobre o tema - tais como Jaccon e Cudo (1989), Santos et al. (2001) e Finotti, Finkler e Silva (2009) — , eles comentam apenas técnicas para entender processos hidrológicos, mas não são voltados para compreender o mecanismo de geração de vazão. Para entender melhor esse mecanismo, a tensiometria em encostas é fundamental.

Os parâmetros morfométricos de bacias hidrográficas são necessários para a caracterização da área de estudo. Além disso, podem ser utilizados para estimar parâmetros hidrológicos, como o tempo de concentração, e são requeridos também na aplicação de alguns modelos de regionalização hidrológica, por exemplo.

O presente estudo apresentou a importância do levantamento topográfico mais detalhado para o estudo hidrológico de pequenas bacias a fim de estimar mais corretamente os valores desses parâmetros morfométricos da bacia. Na impossibilidade do levantamento topográfico, o procedimento apresentado para ajustar a rede de drenagem a nascentes e confluências observadas em campo é pouco oneroso e já apresenta significativa melhora.

Ao longo do monitoramento é necessário aprimorar e corrigir alguns procedimentos e instalações. No início do monitoramento, percebeu-se que muitas folhas se acumulavam no vertedor, interferindo na medição de nível pelo sensor de nível. A providência tomada foi a instalação de uma tela com uma armação protegendo o lago formado pelo vertedor. Assim, o monitoramento hidrológico (mesmo automatizado) é uma atividade que requer constante manutenção e aprimoramento do sistema.

\section{AGRADECIMENTOS}

Agradecemos ao Conselho Nacional de Pesquisa (CNPq) eà Financiadora de Estudos e Projetos (FINEP) pelo financiamento da pesquisa e bolsas de estudos. Agradecemos também à empresa Battistella Florestal pela autorização de uso da área para pesquisa, e ao funcionário Purungo, que nos apresentou a bacia. E agradecemos ainda a todos os integrantes do Laboratório de Hidrologia (LabHidro) da Universidade Federal de Santa Catarina (UFSC) pelo auxílio no trabalho em campo e pelas valiosas discussões hidrológicas. 


\section{REFERÊNCIAS}

ALMEIDA, A.C.; SOARES, J.V. (2003) Comparação entre uso de água em plantações de Eucalyptusgrandis e floresta ombrófila densa (mata atlântica) na costa leste do Brasil. Longo do seu ciclo de crescimento. Árvore, v. 27, n. 2, p. 159-170.

ANDERSON, M.G.; BURT, T.P. (Eds.). (1990) Process studies in hillslope hydrology.Chichester: John-Wiley. 539 p.

BRASIL. (1997) Lei n.o 9.433, de 8 de janeiro de 1997. Institui a Política Nacional de Recursos Hídricos, cria o Sistema Nacional de Gerenciamento de Recursos Hídricos, regulamenta o inciso XIX do art. 21 da Constituição Federal, e altera o art. 1.0 da Lei n.0 8.001, de 13 de março de 1990, que modificou a Lei n. ${ }^{0}$ 7.990, de 28 de dezembro de 1989. Diário Oficial da União. 470 p.

BRASIL. (2006) Lei n.0 11.428, de 22 de dezembro de 2006. Dispõe sobre a utilização e proteção da vegetação nativa do bioma mata atlântica, e dá outras providências. Diário Oficial da União, n. 246, p. 1.

BRASIL. Ministério do Meio Ambiente. (2002) Portaria n. 0 49, de 6 de fevereiro de 2002.Cria um Grupo de Trabalho para elaborar estudo e apresentar propostas de preservação dos remanescentes e de recuperação de áreas degradadas com o objetivo de promover a conservação do ecossistema da floresta ombrófila mista no estado de Santa Catarina. Diário Oficial da União, n. 27. 63 p.

CHAFFE, P.L.B.; KOBIYAMA, M.; YAMASHIKI, Y.; TAKARA, K. (2010) Is interception information important for rainfall-runoff modeling? Annual Journal of Hydraulic Engineering, v. 54, p. 73-78.

DE OLIVEIRA LEITE, J. (1985) Interflow, overland flow and leaching of natural nutrients on an alfisol slope of southern Bahia, Brazil. Journal of Hydrology, v. 80, n. 1-2, p. 77-92.

FINOTTI, A.R.; FINKLER, R.; SILVA, M.D. (2009) Monitoramento de recursos hídricos em áreas urbanas. Caxias do Sul: Educs. 270 p.

FUJIEDA, M.; KUDOH, T; CICCO, V:; CALVARCHO, J.L. (1997) Hydrological processes attwo subtropical forestcatchments: the Serra do Mar, São Paulo, Brazil. Journal of Hydrology, v. 196, n. 1-4, p. 26-46.

FUJIEDA, M.; KUDOH, T.; MASHIMA, Y. (1993) Hydrological processes in the Serra do Mar, São Paulo, Brazil. In: PROCEEDINGS OF THE YOKOHAMA SYMPOSIUM: HYDROLOGY OF WARM HUMID REGIONS, 1993, Yokohama. Anais... Yokohama: IAHS. p. 43-51. (n.216.)

GOLDENFUM, J.A. (2001) Pequenas bacias hidrológicas: conceitos básicos.In:PAIVA,J.B.D.PAIVA,E.M.C.D.(Orgs.).Hidrologiaaplicadaàgestão de pequenas bacias hidrográficas. Porto Alegre: Editora ABRH, p. 3-13.

GOMES, M.A.; LANI, J.L.; COSTA, L.M.; PONTES, L.M.; FIGUEREDO, N.A.; BARDALES, N.G. (2012) Solos, manejo e aspectos hidrológicos na bacia hidrográfica do Araújos, Viçosa - MG. Revista Árvore, v. 36, n. 1, p. 93-102.

JACCON, G.; CUDO, K.J. (1989) Curva-chave: análise e traçado. Brasília: DNAEE. 273 p.

KIRKBY, M.J. (Ed.). (1978) Hillslope hydrology. Chichester: JohnWiley.389 p.
KIRPICH, T.P. (1940) Time of concentration of small agricultural watersheds. Journal of Civil Engineering, v. 10, n. 6. 362 p.

LOUKAS, A.; QUICK, M.C. (1996) Physically-based estimation of lag time for forested mountainous watersheds. Hydrological Sciences Journal, v. 41, n. 1, p. 1-19.

MARANGON, F.H.S.; SANTOS, I. (2O12) Modelagem hidrológica com o TOPOG_SBM na bacia do RioSaci(SC) considerandoa dinâmica espacial e temporal das áreas saturadas. RevistaGeoNorte, v. 3, n. 10, p. 66-83.

MENDONÇA, L.A.R.; VÁSQUEZ, M.A.N.; FEITOSA, J.V;; OLIVEIRA, J.F; FRANCA, R.M.; VÁSQUEZ, E.M.F.; FRISCHKORN, H. (2009) Avaliação da capacidade de infiltração de solossubmetidos a diferentes tipos de manejo. Revista Engenharia Sanitária e Ambiental, v. 14, n. 1, p. 89-98.

NACE, R.L. (1974) General evolution of the concept of the hydrological cycle. In: United Nations Educational, Scientific and Cultural Organization (UNESCO). Three centuries of scientific hydrology: Key papers submitted on the occasion of the celebration of the Tercentenary of Scientific Hydrology, Paris: UNESCO-World Meteorological OrganizationInternational Association of Hydrological Sciences. p. 40-51.

NAKANO, H. (1976) Hidrologia florestal. Tóquio: Kyoritsu. 228 p.

PORTO, R.M. (2006) Hidráulica básica. 4. ed. São Carlos: Edusp. 519 p.

SANTOS, I.; FILL, H.D.; SUGAI, M.R.B.; BUBA, H.; KISHI, R.T.; MARONE, E.; LAUTERT, L.F. (2001) Hidrometria aplicada. Curitiba: Lactec. 372 p.

SIMAS, M.J.; HAWKINS, R.H. (1996) Lag time characteristics for small watersheds in the U.S. Water Resources Engineering'98, p. 1290-1296.

SOUZA, M.M.; GASTALDINI, M.C.C. (2014) Avaliação da qualidade da água em baciashidrográficas com diferentes impactos antrópicos. Revista Engenharia Sanitária e Ambiental, v. 19, n. 3, p. 263-274.

STEWART, B. (2015) Measuring what we manage: the importance of hydrological data to water resources management. In: INTERNATIONAL ASSOCIATION OF HYDROLOGICAL SCIENCES, Paris, France, 2014. Anais..., Paris, v.366, p. 80-85.

TODD, D.K.; MAYS, L.W. (2005) Groundwater hydrology. 3. ed. Nova York: John Wiley and Sons. 636 p.

TSUBOYAMA, Y:; SIDLE, R.C.; NOGUCHI, S.; MURAKAMI, S.; SHIMIZU, T. (2000) A zero-order basin: its contribution to catchment hydrology and internal hydrological processes. Hydrological Processes, v. 14, p. 387-401.

UCHIDA, T.; ASANO, Y.; ONDA, Y.; MIYATA, S. (2005) Are headwaters just the sum of hillslopes? Hydrological Processes, v. 19, p. 3251-3261.

UHLENBROOK, S. (2006) Catchment hydrology: a science in which all processes are preferential. Hydrological Processes, v. 20, n. 16, p. 3581-3585

WHITEHEAD, P.G.; ROBINSON, M. (1993) Experimental basin studies: an international and historical perspective of forest impacts. Journal of Hydrology, v. 145, n. 3-4, p. 217-230. 